\title{
First Principles Study on the Stability and Electronic Structures of 7,8-Dichloro-4-Oxo-4H-Chromene-3-Carbaldehyde
}

\section{Pek-Lan Toh ${ }^{1, a^{*}}$, Montha Meepripruk ${ }^{2, b}$, Lee Sin Ang ${ }^{3, c}$, Shukri Sulaiman ${ }^{4, d}$ and Mohamed Ismail Mohamed-Ibrahim ${ }^{4, e}$}

\author{
${ }^{1}$ Department of Electronic Engineering, Faculty of Engineering and Green Technology, \\ Universiti Tunku Abdul Rahman, 31900 Perak, Malaysia
}
${ }^{2}$ School of Chemistry, Institute of Science and Technology, Kampheang Phet Rajabhat University, Kampheang Phet 62000, Thailand

\author{
${ }^{3}$ Faculty of Applied Sciences, Universiti Teknologi Mara, 02600 Perlis, Malaysia \\ ${ }^{4}$ Computational Chemistry and Physics Laboratory, School of Distance Education, \\ Universiti Sains Malaysia, 11800 Penang, Malaysia \\ apeklan_toh@yahoo.com.my, ${ }^{b}$ montha_mee@hotmail.com, canglee631@perlis.uitm.edu.my, \\ dshukri@usm.my, emi-mi@usm.my
}

Keywords: Density Functional Theory (DFT), 7,8-Dichloro-4-Oxo-4H-Chromene-3-Carbaldehyde, geometric parameters, electronic structures, Mulliken atomic charges.

\begin{abstract}
The molecular structures and electronic properties of 7,8-Dichloro-4-Oxo-4H-Chromene3-Carbaldehyde, $\mathrm{C}_{10} \mathrm{H}_{4} \mathrm{Cl}_{2} \mathrm{O}_{3}$ have been studied using Density Functional Theory (DFT) method. The calculation of geometry optimization was conducted to find the local energy minimum of $\mathrm{C}_{10} \mathrm{H}_{4} \mathrm{Cl}_{2} \mathrm{O}_{3}$ molecular system. The equilibrium geometries were used to determine the HOMOLUMO gaps, Mulliken atomic charges, and other electronic structures of $\mathrm{C}_{10} \mathrm{H}_{4} \mathrm{Cl}_{2} \mathrm{O}_{3}$. The significant findings from DFT/B3LYP functional within the basis sets of $6-31 \mathrm{G}^{* *}, 6-31++\mathrm{G}^{* *}$, $6-311 \mathrm{G}^{* *}$, and $6-311++\mathrm{G}^{* *}$ show that the optimized geometries of $\mathrm{C}_{10} \mathrm{H}_{4} \mathrm{Cl}_{2} \mathrm{O}_{3}$ are in good agreement with that of measurement data. To further investigate this, using a variety of basis sets (3-21G, 6-31G, 6-31++G, 6-31G**, 6-31++G**, 6-311G, 6-311++G, 6-311G**, and 6-311++G**), it is found that the calculated total energy values of $\mathrm{C}_{10} \mathrm{H}_{4} \mathrm{Cl}_{2} \mathrm{O}_{3}$ are close to each other. Similarly, the computed HOMO-LUMO energy gaps obtained are also close to each other. Using the scheme of Mulliken Population Analysis (MPA), the trend of findings are the same for both cases of B3LYP/6-31G and B3LYP/6-31G** level of calculations. For the method of B3LYP/6-31G, it is clearly found that $\mathrm{C}_{4}$ and $\mathrm{C}_{6}$ have the highest positively charge, with the corresponding values about +0.284 and +0.238 , respectively. On the other hand, the charge values of +0.157 and +0.206 are found on $\mathrm{Cl}_{1}$ and $\mathrm{Cl}_{2}$ atoms. The atoms of $\mathrm{O}_{1}, \mathrm{O}_{2}$, and $\mathrm{O}_{3}$ have the negatively charges, with the values of about $0.398,-0.512$, and -0.424 , respectively. Similarly, in the case of DFT/B3LYP/6$31 \mathrm{G}^{* *}$ level of theory, the computed charge values of $\mathrm{C}_{2}$ and $\mathrm{C}_{4}$ are about +0.311 and +0.393 , respectively. Furthermore, the $\mathrm{Cl}_{1}$ and $\mathrm{Cl}_{2}$ atoms have the positively charge values of about +0.043 and +0.070 , whereas for the $\mathrm{O}_{1}, \mathrm{O}_{2}$, and $\mathrm{O}_{3}$ atoms, the charges values obtained are about -0.421 , -0.467 , and -0.498 , respectively.
\end{abstract}

\section{Introduction}

Many substituted 3-Formylchromone has been synthesized, and their properties have been studied [1-6]. There have been recently received considerable attentions as a subject to the academic researches. Several 3-Formylchromone derivatives could also serve as key synthetic building blocks for the molecular construction in the biological fields and various medical chemistry applications primarily [1-6]. In the literature, a number of experimental studies concerning 3-Formylchromone derivatives have been reported. In 2014, Parveen et al. characterized a series of new substituted 3-formylchromone derivatives using Knoevenagel Condensation (KC) technique [1]. They also worked on Mass Spectrometry (MS), Infrared (IR), and Raman spectroscopy studies of these new substituted 3-formylchromone. The experimental data clearly indicates that these synthesized 
3-formylchromone derivatives bind strongly with DNA molecules. The structures of substituted 3-formylchromone obtained are quite similar to bis-intercalators of DNA, which can be reserved as a template for future studies in the therapeutic purposes. In 2015, Ishikawa also studied the new crystal structure and characterization of 7,8-Dichloro-4-Oxo-4H-Chromene-3-Carbaldehyde, $\mathrm{C}_{10} \mathrm{H}_{4} \mathrm{Cl}_{2} \mathrm{O}_{3}$ using X-ray crystallography, IR, Raman spectroscopy, and others [6]. Density Functional Theory (DFT) calculations nowadays have been widely used as powerful method to investigate geometries and electronic properties of various materials [7-13]. Babar et al., in 2014, investigated the Highest Occupied Molecular Orbital (HOMO) and Lowest Unoccupied Molecular Orbital (LUMO) energies of a series of new substituted 2-anilinothiazoles derivatives using the DFT/B3LYP/6-31G* level of theory [7]. The calculation results found that the 2-anilinothiazoles substitutions have no significant effect on the HOMO-LUMO energy gaps. In 2015, Singh reported the effect on geometrical parameters, atomic charges, and vibrational frequencies of uracil and 5-Methyuracil (Thymine) molecules [9]. The computed vibrational frequencies obtained are in good agreement with experimental measurements. Also, Toh et al., in 2015, used the DFT method employing the three functionals with the $6-31++\mathrm{G}^{* *}$ and $6-311++\mathrm{G}^{* *}$ basis sets to investigate the electronic structures, and hyperfine interactions of muonium in imidazole and 1-Methylimidazole molecular system, respectively [11]. The results found that the calculated total energy values obtained of both muoniated systems are consistent with measurement data. Furthermore, there is no reported computational investigation of 7,8-Dichloro-4-Oxo-4H-Chromene-3-Carbaldehyde, $\mathrm{C}_{10} \mathrm{H}_{4} \mathrm{Cl}_{2} \mathrm{O}_{3}$ compound in the literature. To the best of our knowledge, first principles DFT procedure was carried out to study the geometric parameters, local energy minima, Mulliken atomic charges, and others for the $\mathrm{C}_{10} \mathrm{H}_{4} \mathrm{Cl}_{2} \mathrm{O}_{3}$ molecular system. The overall details of the computational methodology, results, discussion, and summary are provided in the following sections.

\section{Computational Methodology}

All Density Functional Theory (DFT) calculations, including geometry optimization and single point calculation in this work were carried out using the Density Functional Theory (DFT) procedure within Gaussian 03 and Gaussian 09 program packages [14,15]. A single molecule of 7,8-Dichloro4-Oxo-4H-Chromene-3-Carbaldehyde, $\mathrm{C}_{10} \mathrm{H}_{4} \mathrm{Cl}_{2} \mathrm{O}_{3}$ was chosen to simulate the local host environment. The sketch of molecular structure of the $\mathrm{C}_{10} \mathrm{H}_{4} \mathrm{Cl}_{2} \mathrm{O}_{3}$ with atom numbering is illustrated in Fig. 1. Using the $\mathrm{C}_{10} \mathrm{H}_{4} \mathrm{Cl}_{2} \mathrm{O}_{3}$ molecular system, geometry optimization calculations at the DFT/B3LYP level of theory with $3-21 \mathrm{G}, 6-31 \mathrm{G}, 6-31++\mathrm{G}, 6-31 \mathrm{G}^{* *}, 6-31++\mathrm{G}^{* *}, 6-311 \mathrm{G}$, 6-311++G, 6-311G**, and 6-311++G** basis sets were performed to find the local energy minimum of $\mathrm{C}_{10} \mathrm{H}_{4} \mathrm{Cl}_{2} \mathrm{O}_{3}$. The optimized geometries of $\mathrm{C}_{10} \mathrm{H}_{4} \mathrm{Cl}_{2} \mathrm{O}_{3}$ were then used to determine the total energy and Frontier molecular orbital energies, particularly the Highest Occupied Molecular Orbital (HOMO) and Lowest Unoccupied Molecular Orbital (LUMO) of $\mathrm{C}_{10} \mathrm{H}_{4} \mathrm{Cl}_{2} \mathrm{O}_{3}$. Using the Mulliken population analysis (MPA), the atomic charges of $\mathrm{C}_{10} \mathrm{H}_{4} \mathrm{Cl}_{2} \mathrm{O}_{3}$ were also calculated.

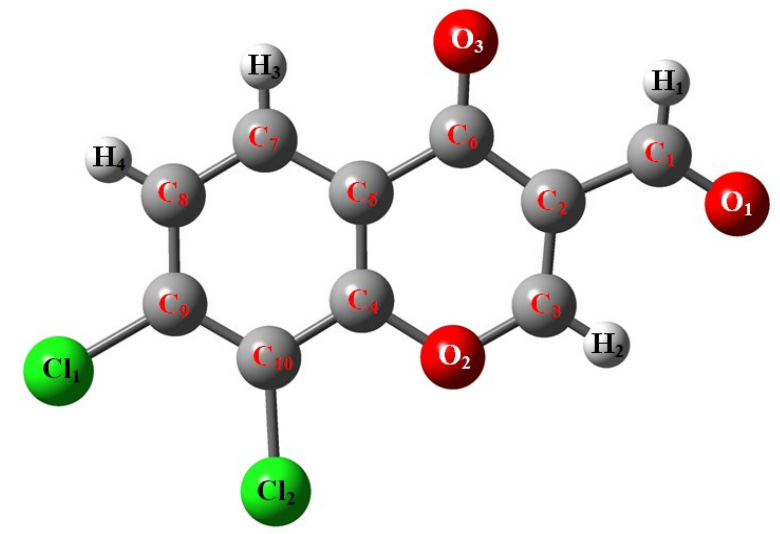

Fig. 1: The numbering system used for 7,8-Dichloro-4-Oxo-4H-Chromene-3-Carbaldehyde, $\mathrm{C}_{10} \mathrm{H}_{4} \mathrm{Cl}_{2} \mathrm{O}_{3}$. 


\section{Results and Discussion}

The optimized molecular geometries of 7,8-Dichloro-4-Oxo-4H-Chromene-3-Carbaldehyde, $\mathrm{C}_{10} \mathrm{H}_{4} \mathrm{Cl}_{2} \mathrm{O}_{3}$ are investigated by DFT/B3LYP method using several basis sets of 3-21G, 6-31G, $6-31++\mathrm{G}, 6-31 \mathrm{G}^{* *}, 6-31++\mathrm{G}^{* *}, 6-311 \mathrm{G}, 6-311++\mathrm{G}, 6-311 \mathrm{G}^{* *}$, and $6-311++\mathrm{G}^{* *}$. In this work, the calculated optimized bond lengths, bond angles, and dihedral angles obtained for the title compound are compared with the experimental values and summarized in Table 1. It can be clearly observed from the table that the optimized bond lengths at 6-31G**, 6-31++G**, 6-311G**, and $6-311++\mathrm{G}^{* *}$ basis sets are in rather good agreement with the experimental data, which reported by Ishikawa [6]. The overall computational data are only different with those of experimental values in the range from $0.01 \%$ to $2.5 \%$. While for the other basis sets of $3-21 \mathrm{G}, 6-31 \mathrm{G}, 6-31++\mathrm{G}, 6-311 \mathrm{G}$, and $6-311++\mathrm{G}$, the calculated bond lengths obtained are slightly different from the experimental ones for a range of $0.1 \%-5.0 \%$. Furthermore, the double bond of $\mathrm{C}_{1}-\mathrm{O}_{1}$ is the shortest bond length among the bonds in $\mathrm{C}_{10} \mathrm{H}_{4} \mathrm{Cl}_{2} \mathrm{O}_{3}$. While the bond lengths of $\mathrm{C}_{9}-\mathrm{Cl}_{1}$ and $\mathrm{C}_{9}-\mathrm{Cl}_{1}$ have the longest values in the title molecule, and the order of these $\mathrm{C}-\mathrm{Cl}$ bonds are equal to 1 . In the case of bond angles, the computed values obtained are close to that of experimental results, which given by Ishikawa [6]. Using DFT/B3LYP simulation approach within a variety of basis sets $(3-21 \mathrm{G}, 6-31 \mathrm{G}$, $6-31++\mathrm{G}, 6-31 \mathrm{G}^{* *}, 6-31++\mathrm{G}^{* *}, 6-311 \mathrm{G}, 6-311++\mathrm{G}, 6-311 \mathrm{G}^{* *}$, and $\left.6-311++\mathrm{G}^{* *}\right)$, the calculated bond angles are only in the range of $0.1 \%-1.1 \%$ different with those of measurement values [6]. For the dihedral angles of $\mathrm{C}_{10} \mathrm{H}_{4} \mathrm{Cl}_{2} \mathrm{O}_{3}$, the computed values at the DFT/B3LYP level within a variety of basis sets are found to vary in the range of $2.93^{\circ}-3.14^{\circ}$, which are slightly smaller to the measurement data [6].

Table 1: Selected optimized geometrical parameters of $\mathrm{C}_{10} \mathrm{H}_{4} \mathrm{Cl}_{2} \mathrm{O}_{3}$ molecular system.

\begin{tabular}{|c|c|c|c|c|c|c|c|c|c|c|}
\hline & 3-21G & 6-31G & $6-31++G$ & $6-31 G^{* *}$ & $6-31 G * *$ & 6-311G & 6-311++G & $6-311 G * *$ & $6-311++G^{* *}$ & $\begin{array}{c}\text { Experiment } \\
{[6]}\end{array}$ \\
\hline & \multicolumn{10}{|c|}{ Bond Length (Angstrom) } \\
\hline $\mathrm{C}_{1}-\mathrm{O}_{1}$ & 1.237 & 1.244 & 1.246 & 1.218 & 1.220 & 1.241 & 1.242 & 1.211 & 1.212 & 1.207 \\
\hline $\mathrm{C}_{1}-\mathrm{C}_{2}$ & 1.477 & 1.477 & 1.478 & 1.483 & 1.484 & 1.476 & 1.476 & 1.485 & 1.485 & 1.484 \\
\hline $\mathrm{C}_{3}-\mathrm{O}_{2}$ & 1.373 & 1.367 & 1.366 & 1.342 & 1.342 & 1.367 & 1.365 & 1.340 & 1.339 & 1.346 \\
\hline $\mathrm{C}_{4}-\mathrm{O}_{2}$ & 1.393 & 1.396 & 1.395 & 1.372 & 1.373 & 1.396 & 1.395 & 1.370 & 1.370 & 1.374 \\
\hline $\mathrm{C}_{6}-\mathrm{O}_{3}$ & 1.244 & 1.254 & 1.255 & 1.228 & 1.230 & 1.253 & 1.253 & 1.221 & 1.223 & 1.233 \\
\hline $\mathrm{C}_{9}-\mathrm{C}_{10}$ & 1.383 & 1.393 & 1.393 & 1.398 & 1.399 & 1.389 & 1.390 & 1.394 & 1.394 & 1.387 \\
\hline $\mathrm{C}_{9}-\mathrm{Cl}_{1}$ & 1.809 & 1.805 & 1.804 & 1.741 & 1.741 & 1.806 & 1.806 & 1.741 & 1.740 & 1.723 \\
\hline \multirow[t]{2}{*}{$\mathrm{C}_{10}-\mathrm{Cl}_{2}$} & 1.798 & 1.795 & 1.795 & 1.735 & 1.735 & 1.797 & 1.797 & 1.735 & 1.734 & 1.723 \\
\hline & \multicolumn{10}{|c|}{ Bond Angle (Degree) } \\
\hline $\mathrm{C}_{2}-\mathrm{C}_{1}-\mathrm{O}_{1}$ & 123.35 & 122.96 & 122.93 & 123.50 & 123.43 & 122.90 & 122.85 & 123.65 & 123.56 & 123.78 \\
\hline $\mathrm{C}_{3}-\mathrm{O}_{2}-\mathrm{C}_{4}$ & 118.23 & 119.21 & 119.41 & 119.04 & 119.26 & 119.29 & 119.43 & 119.03 & 119.17 & 118.30 \\
\hline $\mathrm{C}_{2}-\mathrm{C}_{6}-\mathrm{O}_{3}$ & 123.63 & 122.95 & 122.82 & 123.53 & 123.38 & 122.87 & 122.83 & 123.58 & 123.50 & 123.48 \\
\hline $\mathrm{C}_{5}-\mathrm{C}_{6}-\mathrm{O}_{3}$ & 122.80 & 122.11 & 122.01 & 122.72 & 122.60 & 122.00 & 121.96 & 122.77 & 122.68 & 122.34 \\
\hline $\mathrm{C}_{3}-\mathrm{C}_{9}-\mathrm{Cl}_{1}$ & 118.30 & 118.11 & 118.14 & 118.51 & 118.54 & 118.08 & 118.12 & 118.51 & 118.53 & 119.33 \\
\hline $\mathrm{C}_{10}-\mathrm{C}_{9}-\mathrm{Cl}_{1}$ & 120.41 & 120.78 & 120.78 & 120.68 & 120.69 & 120.74 & 120.74 & 120.68 & 120.69 & 119.94 \\
\hline $\mathrm{C}_{9}-\mathrm{C}_{10}-\mathrm{Cl}_{2}$ & 122.46 & 122.45 & 122.37 & 122.37 & 122.32 & 122.46 & 122.41 & 122.34 & 122.34 & 122.86 \\
\hline \multirow[t]{2}{*}{$\mathrm{C}_{4}-\mathrm{C}_{10}-\mathrm{Cl}_{2}$} & 118.49 & 119.30 & 119.38 & 119.50 & 119.58 & 119.32 & 119.34 & 119.46 & 119.50 & 118.83 \\
\hline & \multicolumn{10}{|c|}{ Dihedral Angle (Degree) } \\
\hline $\mathrm{Cl}_{2}-\mathrm{C}_{10}-\mathrm{C}_{4}-\mathrm{O}_{2}$ & 2.93 & 3.09 & 3.13 & 3.07 & 3.08 & 3.14 & 3.19 & 3.09 & 3.11 & 3.15 \\
\hline
\end{tabular}

In Table 2, the total energies and HOMO-LUMO gaps of $\mathrm{C}_{10} \mathrm{H}_{4} \mathrm{Cl}_{2} \mathrm{O}_{3}$ at the DFT/B3LYP level within a variety of basis sets $\left(3-21 \mathrm{G}, 6-31 \mathrm{G}, 6-31++\mathrm{G}, 6-31 \mathrm{G}^{* *}, 6-31++\mathrm{G}^{* *}, 6-311 \mathrm{G}, 6-311++\mathrm{G}\right.$, 6-311 $\mathrm{G}^{* *}$, and $\left.6-311++\mathrm{G}^{* *}\right)$ are presented. According to the data from the table, the computed total energies of $\mathrm{C}_{10} \mathrm{H}_{4} \mathrm{Cl}_{2} \mathrm{O}_{3}$ molecular system are calculated to be in the range from $-41408.704 \mathrm{eV}$ 
to $-41626.097 \mathrm{eV}$. As the value of $-41626.097 \mathrm{eV}$ obtained from the basis set of $6-311++\mathrm{G}^{* *}$ are chosen to be a zero energy, the total energy values of the other basis sets $(3-21 \mathrm{G}, 6-31 \mathrm{G}, 6-31++\mathrm{G}$, $6-31 \mathrm{G}^{* *}, 6-31++\mathrm{G}^{* *}, 6-311 \mathrm{G}, 6-311++\mathrm{G}$, and $\left.6-311 \mathrm{G}^{* *}\right)$ are only $0.01 \%-1.18 \%$ greater than the DFT/B3LYP/6-311++G** simulation approach. In addition, the HOMO-LUMO energy gaps of $\mathrm{C}_{10} \mathrm{H}_{4} \mathrm{Cl}_{2} \mathrm{O}_{3}$ molecular system are also presented in Table 2. Using DFT/B3LYP computational calculations in a variety of basis sets $\left(3-21 \mathrm{G}, 6-31 \mathrm{G}, 6-31++\mathrm{G}, 6-31 \mathrm{G}^{* *}, 6-31++\mathrm{G}^{* *}, 6-311 \mathrm{G}\right.$, $6-311++\mathrm{G}, 6-311 \mathrm{G}^{* *}$, and 6-311++G**), the HOMO-LUMO energy gaps fall in the range of 4.21 $\mathrm{eV}-4.64 \mathrm{eV}$. Also, it can be noted that the energy gaps of all the basis set are close to each other in this study. As shown in Fig. 2, the molecular orbital diagrams of the frontier orbitals obtained in the study for the title molecule are illustrated using the DFT/B3LYP functional calculation employing the basis set of $6-311 \mathrm{G}^{* *}$. For $\mathrm{C}_{10} \mathrm{H}_{4} \mathrm{Cl}_{2} \mathrm{O}_{3}$ molecular system, the HOMO has mostly $p$ character, respectively, comes from the $p_{x}$ orbitals of the $\mathrm{O}_{1}, \mathrm{O}_{3}, \mathrm{C}_{1}, \mathrm{C}_{2}$, and $\mathrm{C}_{6}$. In other words, the electron distributions of the HOMO diagram are mainly localized on the parts of aldehyde and $\mathrm{C}_{4}-\mathrm{O}_{2}$, respectively. The results, given in the figure, also presented that the LUMO has mostly $p$ character symmetry, where the electron distributions are localized on the whole molecular system.

Table 2: Calculated total and frontier molecular orbital energies $(\mathrm{eV})$ of $\mathrm{C}_{10} \mathrm{H}_{4} \mathrm{Cl}_{2} \mathrm{O}_{3}$.

\begin{tabular}{cccccccccc}
\hline & $\mathbf{3 - 2 1 G}$ & $\mathbf{6 - 3 1 G}$ & $\mathbf{6 - 3 1 + + G}$ & $\mathbf{6 - 3 1 G} * *$ & $\mathbf{6 - 3 1 G} * *$ & $\mathbf{6 - 3 1 1 G}$ & $\mathbf{6 - 3 1 1 + + G}$ & $\mathbf{6 - 3 1 1 G} * *$ & $\mathbf{6 - 3 1 1}^{* *+G^{* *}}$ \\
\hline Total energy & -41133.29 & -41408.70 & -41614.11 & -41614.78 & -41620.30 & -41620.94 & -41619.72 & -41620.14 & -41625.73 \\
HOMO & -4.24 & -7.03 & -7.24 & -7.56 & -7.01 & -7.37 & -7.48 & -7.59 & -7.25 \\
LUMO & -0.02 & -2.51 & -2.75 & -3.07 & -2.38 & -2.76 & -2.97 & -3.09 & -2.61 \\
$\begin{array}{c}\text { HOMO- } \\
\text { LUMO gap }\end{array}$ & 4.21 & 4.52 & 4.49 & 4.49 & 4.62 & 4.61 & 4.51 & 4.50 & 4.64 \\
\hline
\end{tabular}

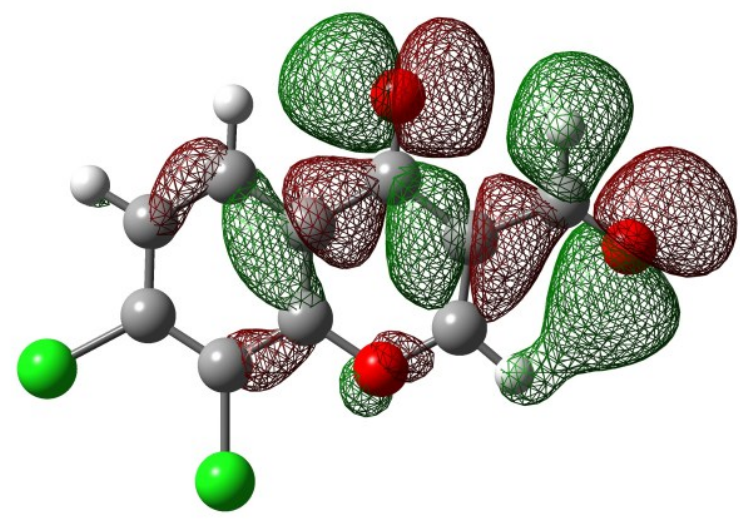

HOMO

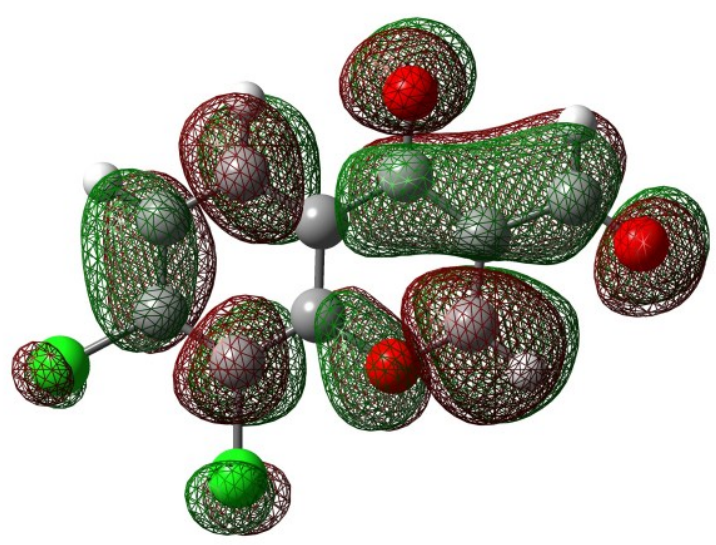

LUMO

Fig. 2: Calculated molecular orbital diagrams of the frontier orbitals of $\mathrm{C}_{10} \mathrm{H}_{4} \mathrm{Cl}_{2} \mathrm{O}_{3}$ at the DFT/B3LYP/6-311G** level of theory.

Using Mulliken Population Analysis (MPA) at B3LYP/6-31G and B3LYP/6-31G** level of calculations, the atomic charge distributions of $\mathrm{C}_{10} \mathrm{H}_{4} \mathrm{Cl}_{2} \mathrm{O}_{3}$ are illustrated in Fig. 3. The results in the case of DFT/B3LYP functional calculations employing with 6-31G basis set, given in Fig. 3(a), clearly indicate that $\mathrm{C}_{4}$ atom has the highest positively charge, with the corresponding value of charge about +0.284 . By following the charge of $\mathrm{C}_{6}$ is determined to be +0.238 in $\mathrm{C}_{10} \mathrm{H}_{4} \mathrm{Cl}_{2} \mathrm{O}_{3}$ molecular system. Furthermore, the computed positively charge of $\mathrm{Cl}_{1}$ and $\mathrm{Cl}_{2}$ atoms, respectively are about +0.157 and +0.206 . While for the oxygen, $\mathrm{O}_{1}, \mathrm{O}_{2}$, and $\mathrm{O}_{3}$ atoms become negatively charges, the charges are calculated to be about $-0.398,-0.512$, and -0.424 , respectively. In this study, the computational data evident that Mulliken atomic charge distributions are dependent on the size of basis sets. However, for both B3LYP/6-31G and B3LYP/ 6-31G** calculations, the trend of results are the same. In the case of DFT/ B3LYP/ 6-31G** level of theory (Fig. 3(b)), both atoms of $\mathrm{C}_{4}$ and $\mathrm{C}_{6}$ becomes more positive than B3LYP/6-31G calculation, respectively, with the corresponding values about +0.311 and +0.393 . For the title molecule, the charges of $\mathrm{Cl}_{1}$ and $\mathrm{Cl}_{2}$ are 
then determined to be about +0.043 and +0.070 , whereas the charges values of $-0.421,-0.467$, and -0.498 are obtained on the $\mathrm{O}_{1}, \mathrm{O}_{2}$, and $\mathrm{O}_{3}$ atoms, respectively.

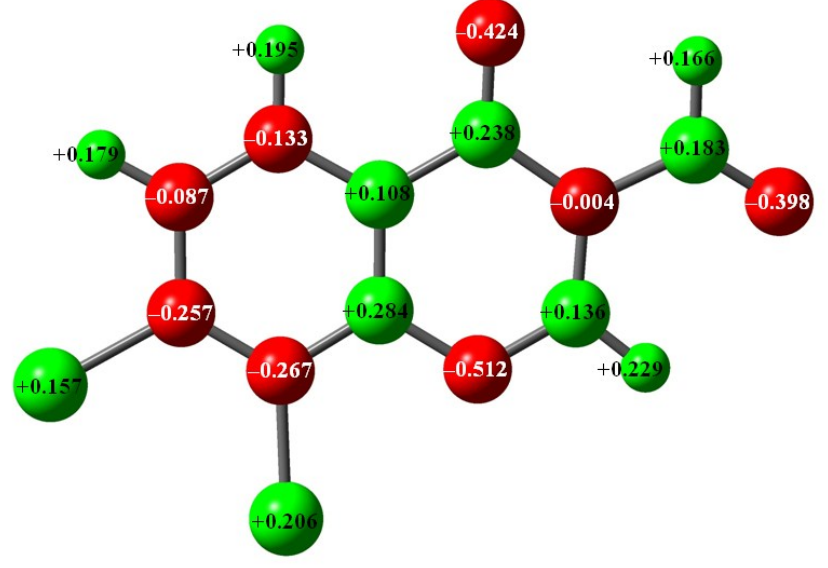

2(a)

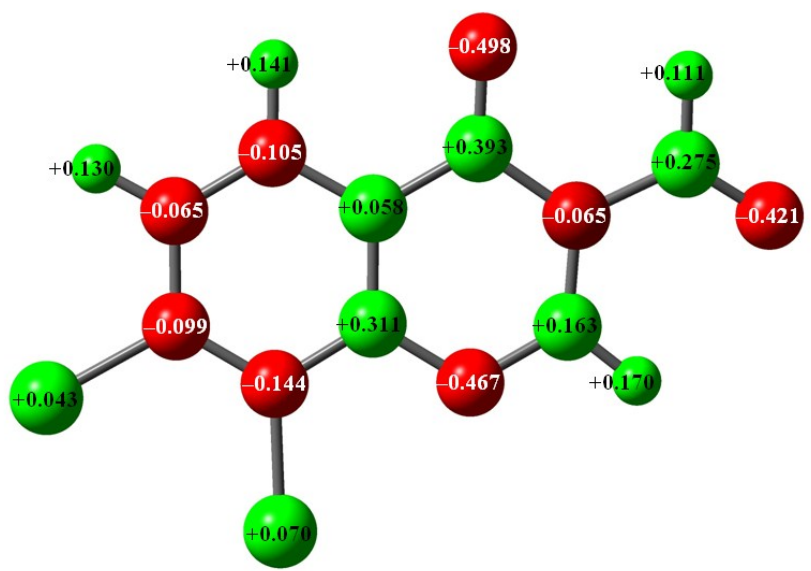

2(b)

Fig. 3: Mulliken atomic charges distribution used for the optimized $\mathrm{C}_{10} \mathrm{H}_{4} \mathrm{Cl}_{2} \mathrm{O}_{3}$ based on the (a) B3LYP/6-31G and (b) B3LYP/6-31G** level of calculations.

\section{Summary}

All computational calculations were carried out using the Gaussian 03 and Gaussian 09 program packages [14,15] within first principles investigation within the Density Functional Theory (DFT) method. In the case of geometrical parameters of $\mathrm{C}_{10} \mathrm{H}_{4} \mathrm{Cl}_{2} \mathrm{O}_{3}$ molecular system, the computed values are close to experimental measurements, which presented by Ishikawa [6]. In addition, the calculated total energies are close to each other using DFT/B3LYP level of calculation within a variety of basis sets $\left(3-21 \mathrm{G}, 6-31 \mathrm{G}, 6-31++\mathrm{G}, 6-31 \mathrm{G}^{* *}, 6-31++\mathrm{G}^{* *}, 6-311 \mathrm{G}, 6-311++\mathrm{G}\right.$, $6-311 \mathrm{G}^{* *}$, and $\left.6-311++\mathrm{G}^{* *}\right)$. Similarly, the HOMO-LUMO energy gaps of title compound obtained are consistent with each other. In the case of Mulliken atomic charges, the computed charges of $\mathrm{C}_{4}$ and $\mathrm{C}_{6}$ atoms are about +0.284 and +0.238 , which have the highest positively charges in the title compound using DFT/B3LYP/6-31G simulation approach. The charges of $\mathrm{Cl}_{1}$ and $\mathrm{Cl}_{2}$ atoms are found to be about +0.157 and +0.206 , while the charge values of $-0.398,-0.512$, and -0.424 , respectively, are obtained on the atoms of $\mathrm{O}_{1}, \mathrm{O}_{2}$, and $\mathrm{O}_{3}$. The similar trend is found in the case of DFT/B3LYP/6-31G** calculation. The charge values of $\mathrm{C}_{4}$ and $\mathrm{C}_{6}$ atoms are about +0.311 and +0.393 . By following the charges of $\mathrm{Cl}_{1}$ and $\mathrm{Cl}_{2}$ atoms are calculated to be about +0.043 and +0.070 , whereas the negatively charge values of $-0.421,-0.467$, and -0.498 are found for the $\mathrm{O}_{1}, \mathrm{O}_{2}$, and $\mathrm{O}_{3}$ atoms, respectively. Further studies are currently being carried out to investigate the effects of cluster size in $\mathrm{C}_{10} \mathrm{H}_{4} \mathrm{Cl}_{2} \mathrm{O}_{3}$ molecular system.

\section{References}

[1] M. Parveen, A.M. Malla, Z. Yaseen, A. Ali, M. Alam, Synthesis, characterization, DNAbinding studies and Acetylcholinesterase inhibition activity of new 3-Formyl chromone derivatives, J. Photochemistry and Photobiology B: Bio. 130 (2014) 179-187.

[2] Y. Ishikawa, Crystal structure of 6-Fluoro-4-Oxo-4H-Chromene-3-Carbaldehyde, Acta Cryst. E. 70 (2014) o 774.

[3] Y. Ishikawa, Crystal structure of 7-Chloro-4-Oxo-4H-Chromene-3-Carbaldehyde, Acta Cryst. E. 70 (2014) 0831.

[4] Y. Ishikawa, Crystal structure of 7-Bromo-4-Oxo-4H-Chromene-3-Carbaldehyde, Acta Cryst. E. 70 (2014) 0996. 
[5] Y. Ishikawa, Crystal structure of 6-Bromo-7-Fluoro-4-Oxo-4H-Chromene-3-Carbaldehyde, Acta Cryst. E. 71 (2015) 857-860.

[6] Y. Ishikawa, Crystal structure of 7,8-Dichloro-4-Oxo-4H-Chromene-3-Carbaldehyde, Acta Cryst. E. 71 (2015) 902-905.

[7] A. Babar, H. Khalid, K. Ayub, S. Saleem, A. Waseem, T. Mahmood, M.A. Munawar, G. Abbas, A.F.Khan, Synthesis, characterization and Density Functional Theory study of some new 2-Anilinothiazoles, J. Molecular Structure 1072 (2014) 221-227.

[8] J.S. Singh, FT-IR and Raman spectra, ab initio and density functional computations of the vibrational spectra, molecular geometries and atomic charges of uracil and 5-Halogenated uracils (5-X-Uracils; $\mathrm{X}=\mathrm{F}, \mathrm{Cl}, \mathrm{Br}, \mathrm{I})$, Spectrochimica Acta Part A: Molecular and Biomolecular Spectroscopy 117 (2013) 502-518.

[9] J.S. Singh, FT-IR and Raman spectra, ab initio and density functional computations of the vibrational spectra, molecular geometries and atomic charges of uracil and 5-Methyluracil (Thymine), Spectrochimica Acta Part A: Molecular and Biomolecular Spectroscopy 137 (2015) 625-640.

[10] P.L. Toh, S. Sulaiman, M.I. Mohamed-Ibrahim, Computational studies of electronic structures and hyperfine interactions of muonium in tetraphenylgermane, Advanced Materials Research 630 (2013) 418-423.

[11]P.L. Toh, S. Sulaiman, M.I. Mohamed-Ibrahim, L.S. Ang, Density functional theory studies of electronic structures and hyperfine interactions of muonium in imidazole, Applied Mechanics and Materials 749 (2015) 134-138.

[12]P.L. Toh, M. Meepripruk, L.S. Ang, S. Sulaiman, M.I. Mohamed-Ibrahim, Density Functional Theory investigations on the geometric and electronic structures of 4-Azidomethyl-6-Isopropyl2H-Chromen-2-One, MATEC Web of Conferences 27 (2015) 01003:1-5.

[13]P.L. Toh, R. Rasmidi, M. Meepripruk, L.S. Ang, S. Sulaiman, M.I. Mohamed-Ibrahim, First principles Density Functional Theory investigation on the structural, energetic, and electronic properties of 6-Bromo-4-Oxo-4H-Chromene-3-Carbaldehyde, Applied Mechanics and Materials 835 (2016) 308-314.

[14] M.J. Frisch, G.W. Trucks, H.B. Schlegel, G.E. Scuseria, M.A. Robb, J.R. Cheeseman, et al., Gaussian 03, Revision C.02, Gaussian, Inc. 2004.

[15] M.J. Frisch, G.W. Trucks, H.B. Schlegel, G.E. Scuseria, M.A. Robb, J.R. Cheeseman, et al., Gaussian 09, Revision D.01, Gaussian, Inc. 2009 